\title{
A CASE.
}

\section{or \\ EXPOSURE}

20 Tu:

\section{VAPOUR OF BURNING. CHARCOAL.}

BY WILLIAM BABINGTON, M.D. R.R.S. :

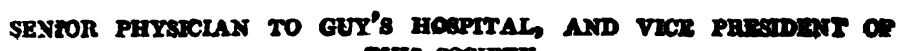
THIS SOCLETY.

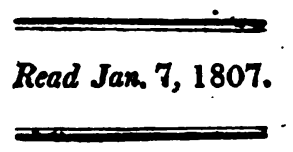

A CONSIDERABLE degree of interest having been excited by the melancholy accident which occurred at the Dolphin, a public-house, in Honeylane Market, on the morning of the 24th of November last, I am induced to offer to the consideration of the Society the following statement, with somie reflections on the subject of it.

William Smith, aged thirty-eight, a waiter bejlonging to the house, and a boy about thirteen years old had, on the preceding night, gone to their bedG 9 
room, both in perfect health, and it was supposed under ordinary circumstances. Between six and seven o'clock in the morning, neither of them having been then seen, a person went to the chamber, and on opening the door found the waiter insensible, and apparently at the point of death; the poor lad lying lifeless on the floor, and a chafing-dish containing some extinguished charcoul placed at the foot of the bedstead. The one who still exhibited signs of life was removed into a larger and more airy apartment; and Mr. Hingeston, of Cheapside, being called, and finding that with stertorous breathing the countenance was rather flushed, the lips livid, the pulse full and strong, and as he conjectured, about ninety in the minute, was induced to take away eight, or at most ten ounces of blood from a vèin in the left arm. At his request I attended to give what assistance might lie in my power. It was little more than seven o'clock when I reached the house, and having been informed of the circumstances under which these unfortunate persons had been discovered, as the respiration, pulse, and heat of him who had been removed into a cool and pure air were distinctly perceptible, I thought it my duty to determine, by actual experiment, whether any thing could be done for the recovery of his companion. With this object in view, a common sized silver catheter being passed from the mouth into the trachea, an artificial process of respiration was instituted by the aid of my friend Mr. Hingeston, and that of his assistant Mr. Gingell, alternately breath- 
ing into the lungs, and forcing out the air so introduced by means of external pressure.

While these gentlemen were engaged in this process, I went to my friend Mr. Allen, in Plough Court, to request his co-operation in the trial of the galvanic influence, as one of the most ready and satisfactory modes of ascertaining whether any remains of life still existed to encourage our further exertions. In this interval the waiter, whom I had: visited as I was quitting the house, had evidently become worse, and the artificial respiration having produced no effect on the boy, we passed several shocks from the galvanic trough, which we had previously found to be acting with considerable power, through his chest and head; but these being equally unproductive of any visible excitement we were reluctantly compelled to think that he had in reality passed from sleep to death. As we now pere ceired that the vital powers were in Smith still further enfeebled, and that unless more active steps were taken, there was reason to think that he also would fall a victim to the accident, we transferred the galvanic apparatus to his apartment, the window of which being open, and there being no fire, the temperature was necessarily that of the atmosphere, about 50 degrees of Fahrenheit. At this time his pulse, instead of being strong and full, as before the bleeding, was weak and quick, and the respirations very imperfect; but the heat of the upper part of the body remained. The poiper of voluntary mo- 
tion was suspended, and the slight convulsive twitchings of the muscles which at frot prevailed had altogether ceased; ordinary impressions no longer appeared to affect his organs of sense. His countenauce was pale, the eyelids closed, the eyes prominent and rolling in their sockets from side to side; the tongue swallen and projected from the mouth, was locked in this position by a spasmodic action of the muscles which raise the lower jaw. At the corners of the mouth there was a copious discharge of frothy saliva. Having passed a galvanic shock through the chest, he instantly, to our surprise, drew his breath deep. The muscles of the abdomen were seen to re-act, though feebly, while those of the face were slightly convulsed, and the eyelids were raised. At each successive application of this powerful agent the respirations were more forcibly performed, and the stroke of the artery at the wrist rose in the same proportion. Having, between eight and nine o'clock procured a bladder filled with oxygen gas, we caused it to be inspired, and we thought that it was followed by an increased activity of the powers of respiration and circulation. As the heat of the body was not deficient, we now sprinkled the face and chest with cold water, which also had the effect of rousing the dormant powers of sensation, as the respiratory muscles were uniformly thrown by it into action, though in a more feeble and interiupted manner than when we employed the galvanic influence. About nine o'clock, having received a large supply of oxygen gas, we repeated the inhalation and the galvanic 
successions alternately, through the chest and head, every half hour, till twelve o'clock, when the galvanit application was discontinued, as the heart, though uniformly excited by it, seemed in the intervals to act more feebly, and we were apprebensive that by exalting the action of one power continually, we might destroy that equilibrium of forces which is necessary to the maintenance of life. Some volatile spirit of hartshorn was rubbed upon the temples and chest, and the vapour of it inhaled; the latter rendered him uneasy and excited coughing. As the extremities were cold, bottles filled with hot water were applied to his feet, and the trunk of the body covered with the bed clothes. About one the surface became moist, and gradually a warm perspiration was diffused over the whole body. The pulse from this time was uniformly fuller and more equable in strength and frequency, and as the respirations became more free, the inhalation of the oxygen was repeated at longer intervals, and about four in the afternoon was entirely desisted from. The spasm of the jaw having subsided in a great degree, and the tongue being reduced, he was allowed some very weak wine and water, which he swallowed, a tea spoonfull at a time, without any apparent difficulty. The pulse had now risen to 120 , and was strong; we, therefore, in the early part of the evening, considered of the propriety of further venæsection; but as the apoplectic stertor was evidently not so great, we determined not to interfere with the efforts of nature; accident, however, accomplished what we 
had hesitated to do; the ligature having slipped from his arm, he lost, before it was noticed, nearly a pound of blood; the pulse sunk, his countenance collapsed, and Mr. Hingeston, who saw him at this period, was apprehensive that he would not survive the debilitating influence of this accidental hæmorrhage. At twelve at night he had, however, recovered from this depression; the pulse was 120 , full, but soft. Repeated glysters had procured a copious stool, and fomentations of the belly had been followed by a free discharge of urine. He was now very restless, and Mr. Gingell kindly stayed with a rela. tion of the poor man during the night, when the exertions of both were requisite to keep him from injuring himself, and rolling out of bed. On the $25^{\text {th }}$, he recovered the use of speech, though very imperfectly. The tongue, when put out, pointed to the left, and the muscles on that side of the face were slightly paralysed, as they had been occasionally observed to be on the preceding day; he complained, when questioned, of pain in his left side; referred to the spot where the wire from the galvanic trough had been applied, and also in his left arm and hand, the latter of which was swelled; the orifice in the arm did not, however, exhibit any signs of inflammation. The cough, which had occasionally distressed him the preceding day, was still rather troublesome. His mental powers seemed much impaired, and he cried bitterly when any person entered the room, a state of imbecility frequently observed in cases of ordinary palsy. He did'not recollect one 
event, or one sensation from the time when on lying down between the hours of eleven and twelve, he saw the charcoal burning bright, till the second or third day after the accident, when he became conscious that he was in a strange room, and felt great distress from being in a situation of which he could form no adequate and satisfactory conception. As the tongue was white, the temperature rather augmented to the touch, and the pulse full, he was kept on a low diet, and the bowels regularly purged. He progressively recovered so far as to be removed by his relations in the course of a few days.

On December 15, he called at my house; at which time he only complained of a slight degree of weakness, more particularly felt in his left arm. His appetite was good. No affection of his head, nor febrile symptoms.

W. BABINGTON.

$J_{\text {AN. } 7,1807 .}$

REFLECTIONS.

THE vapour of burning charcoal has, from times of ancient date, been observed to exert a very deleterious influence on the life of animals; but it is only within these few years that its nature has been 
only within these fer years that its nature bas been developed, and its mode of operating fully appreciated. Modern chemistry has clearly ascertained the composition of atmospheric air, and proved that its capacity for supporting hife chiefly depends upon that constituent principle which, in the language of this science, has been denominated oxygen. It has likewise instructed us that there are many other aerial fluids which possess the ordinary physical properties of the atmosphere, but differ essentially from it in not being subservient to the purposes of respiration. They have hence been distinguished from it by the general term of irrespirable airs or gases, and are destructive of life, either by the exclusion of what is necessary, or by the presence of principles directly injurious to vital energy. Even the atmosphere that we breathe may, by this very process, as well as by various circumstances of chemical combination, be either itself deteriorated, or it may be impregnated with other fluids, and thus be rendered incapable of supporting the function of respiration. We find that the burning of bodies is one of the most common, but effectual ways of producing this change, which analysis teaches us it does by the abstraction or condensation of the oxygenous portion of atmospheric air, and the evolution of new products corresponding with the nature of the inflammable substance which is made the subject of the experiment.

When charcoal in combustion combines with 
oxygen we obtain carbonic acid gas, and at the samp time in proportion to its moisture, more or less hydrocarbonous gas is evolved. The latter is peculiarly fatal to life, and very much increases the danger resulting from exposure to the vapour of burning fuel. The only attempt ever made to breathe it in its undiluted state with which we are acquainted, was that by Mr. Davy, who was very nearly killed by three inspirations. Even when mingled with atmospheric air it very powerfully depresses the living energy. The carbonic acid gas, when unmixed; is also very quickly destructive, and from its specific gravity being considerably greater than that of the atmosphere, it is disposed to accumulate in particular situations, and has in such proved a frequent source of death. Rozier and Davy conclude from their experiments, that the carbonic acid in its undiluted form is wholly irrespirable from its exciting a spasmodic action in which the epiglottis is closed, and the entrance of this fluid into the lungs altogether prevented. The effect produced by it therefore is similar to what occurs in the act of drowning; but if this be the case, and the carbonic acid exert no deleterious influence on the nervous and vascular: systems, how shall we explain the fact, that the loss of irritability in the muscles of animals which have been destroyed by immersion in noxious airs is comparatively greater than in such as are hanged or drowned? The fatality of this gas to the different classes of animals is in general in proportion to the more complicated system of their organization. On 
exposure and the degree of concentration, its effects vary through all the shades of giddiness, pain of the head, anxiety, depression of the powers of life, impeded respiration, loss of voluntary motion and sensation, to the complete suspension of the functions of respiration and circulation. That this pause in the series of vital phenomena shall be final, it is not necessary that any change in the structure of the body shall be observable: we have, however, no right to conclude it such, though appearances should be unfavourable, until our exertions shall have been employed in vain, or that order of combinations which tends to destroy the fabric of organized bodies shall have already commenced. We know not what life is, nor can we without the imputation of temerity speculate on the nature of that mysterious principle which regulates the functions of living beings. While, therefore, there is no apparent lesion of the system, we are called upon to rouse, if possible, its latent energies, by restoring the action of those parts which are more immediately subservient to life; and experience teaches us, that by inflating the lungs we change the condition of the blood, and that there exists a chain of connection between the circulation of blood that has undergone the respiratory process, and the maintenance of that state of the organs of sense and motion which fits them for discharging their respective offices.

Before we proceed to consider the plan followed on the occasion which is the more immediate sub. 
ject of this communication, as the inquiry involves some points of important practical moment, let us endeavour to ascertain what are the appearances which have been remarked in the bodies of animals killed by the vapour of burning fuel. We were refused permission to examine the body of the boy who died; but the researches of others inform us, that there is, in animals furnished with a double heart, a deficiency, either positive or relative, in the quantity of blood contained in the left side of the heart, and in that series of vessels which is connected with it, and an accumulation in the right side of this organ and in its dependent system; and that this condition extends to the veins of the head. In some instances also the ventricles of the brain, it is said, have been observed to contain a frothy serum, occasionally tinged with blood. The lungs have been found collapsed with more or less of frothy liquid in the bronchiæ, and the viscera of the abdomen turgid with blood. Such are the principal anatomical facts; how far do they point out an active and successful mode of proceeding?

The first, and most natural step to be taken, consists in the exposure of the person to a free and pure air, and if the respiration be impeded or suspended we should endeavour to restore this function as speedily as we can, both with a view to the chemical changes to which we have alluded, and to the mechanical effect which the inflation of the lungs 
his in promoting the circulation of the blood through the minute : branches of the pulmonary vessels. It has been insisted upon by very respectable authority, that the abstraction of a small quantity of blood should be the measure first adopted, in order that the heart and the large vessels may, by being relieved from their over distended state, be enabled to contract, and that the brain also may be freed from pressure. But as there is previously to the accident, no disposition to this accumulation, and as the condition of the lungs affords a mechanical obstacle to the transmission of the blood, we deem it more adviseable to remove this by causing them to expand, and if the heart should not then freely act, or the symptoms of pressure should continue equally urgent, it will be full time to have recourse to the lancet. In our patient the pulse certainly sunk after the bleeding, if not owing to this operation, and the accidental bemorrhage which occurred in the evening, it was feared by the attendants.would have proved fatal to him. In what way, may it also be asked, shall we get rid of that accumulation which occurs in the vessels of the liver and other important organs which occupy the abdominal cavity? The restoration of respiration seems to be the natural and most effectual remedy to the altered balance in the cireulating system in general. If, however, the loss of blood be thought necessary, there can be little doubt that opening the jugular vein will most quickly answer the end proposed. 
The inhalation of oxygen gas was directed under the idea of there being an accumulation of that carbonaceous matter which, under the ordinary cirs cumstances of respiration is regularly thrown off; and on account of the evident depression of the vital actions produced by the noxious effects of the carbonic and hydrocarbonous gases. As far as we could judge from the state of the pulse it seemed to exert a stimulating influence on the arterial system at least. The propriety of exciting the heart by electricity previous to the establishment of the respiratory process has been questioned by many. On the present occasion we employed the galvanic modification of this principle, and its effect in promoting a deep and complete inspiration, followed by a more vigorous action of the heart and arteries was strongly conspicuous. As the galvanic apparatus is very portable, and admits of easy application, and as the evolution of this principle is not affected by the state of the atmosphere, it seems to be preferable in cases of this kind to the ordinary form of electricity. By diminishing or increasing the number of compartments when we make use of a trough, we can completely regulate the quantity of the power that we employ.

The introduction of fluids into the stomach is not an easy process in many cases of suspended animation, as trismus is by no means an uncommon occurrence. In such instances, however, this is a circumstance of secondary importance. 
Portal, and other French writers, strongly recom: mend the employment of acids.

In Russia, where accidents of this description are very common, it is the general practice to rub the body with snow, and it is said with the happiest effect. What may be the state of the animal temperature in this affection is at present merely a matter of conjecture. The skin is for the most part warm, but as yet we have no thermonetric observations. The Russian plan is probably of use, from the strong impression which is made upon the skin as a sentient orgau. The sprinkling of cold water upon the face and breast is a less energetic application of the same principle, but has considerable effect in rousing persons both from this state and that of syricope. On the present occasion it constantly produced a visible and marked contraction of the respiratory muscles; though inferior in degree to that resulting from the galvanic stimulus. It is also a well known fact that the recovery of the dogs which are made the subjects of experiment in the Grotto del Cani, is much favoured by their being plunged into a neighbouring lake.

In some cases warmth may be required to be employed, and glysters form an easy mode' of effecting this, and at the same time of administering stimulants.

The application of bottles filled with hot water to 
the feet was the mode followed with Smith, when the apparent depression of the vital powers seemed to demand the aid of artificial heat, and it probably contributed to induce the general and copious perspiration which shortly afterwards broke out.

The torpor of the bowels and urinary organs in Smith were but a part of that general inactivity which arose from the obstructed action of the vital. functions, and the directly poisonous influence of the vapour.

It is of advantage in such cases, to apply volatile alkali, or other pungent bodies to the inside of the nostrils. Whatever promotes sneezing or coughing gives a succussion to the diaphragm, and its antagonist muscles, and tends to re-establish the process of respiration.

Some care will be requisite in the after treatment to guard against any morbid increase of action.The subsequent febrile condition which occurred in our patient was neither severe nor of long continuance.

Whatever plan we adopt, our measures must be promptly and steadily carried into execution; and we may expect that our perseverance will occasionally be put to the test by the interference of some officious person. We were under the necessity of using threats to one of Smith's relations, who would 
willingly have consigned him to an untimely grave. to free him from the misery and pain which she conceived we were cruelly inflicting. Happily, however, our endeavours to restore him succeeded. The exertions made to recover the poor boy, probably proved ineffectual, from the actions of life having been irrerocably suspended by the situation into which he was thrown. In falling out of bed, he was immediately exposed to the concentrated stratum of noxious air which occupied the lower part of the room.

It is to be regretted, that frequently as such accidents have occurred, the danger of sleeping in close. rooms in which fires have been kindled, is still not sufficiently understood. From the testimony of the survivor on this melancholy occasion, it does not appear that he or his unfortunate companion were at all aware of the very perilous circumstances in which they placed themselves. 